\title{
Financeirização do território e circuitos da economia urbana em Alagoas.
}

\section{Paul Clívilan Santos Firmino}

\section{(2) OpenEdition \\ 1 Journals}

\section{Edição electrónica}

URL: https://journals.openedition.org/espacoeconomia/18770

DOI: 10.4000/espacoeconomia.18770

ISSN: 2317-7837

\section{Editora}

Núcleo de Pesquisa Espaço \& Economia

\section{Refêrencia eletrónica}

Paul Clívilan Santos Firmino, «Financeirização do território e circuitos da economia urbana em Alagoas.», Espaço e Economia [Online], 21 | 2021, posto online no dia 12 julho 2021, consultado o 17 julho 2021. URL: http://journals.openedition.org/espacoeconomia/18770 ; DOI: https://doi.org/ 10.4000/espacoeconomia.18770

Este documento foi criado de forma automática no dia 17 julho 2021.

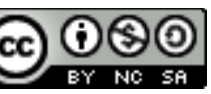

Espaço e Economia - Revista brasileira de geografia econômica est mise à disposition selon les termes de la licence Creative Commons Attribution - Pas d'Utilisation Commerciale - Partage dans les Mêmes Conditions 4.0 International. 


\section{Financeirização do território e circuitos da economia urbana em Alagoas.}

\section{Paul Clívilan Santos Firmino}

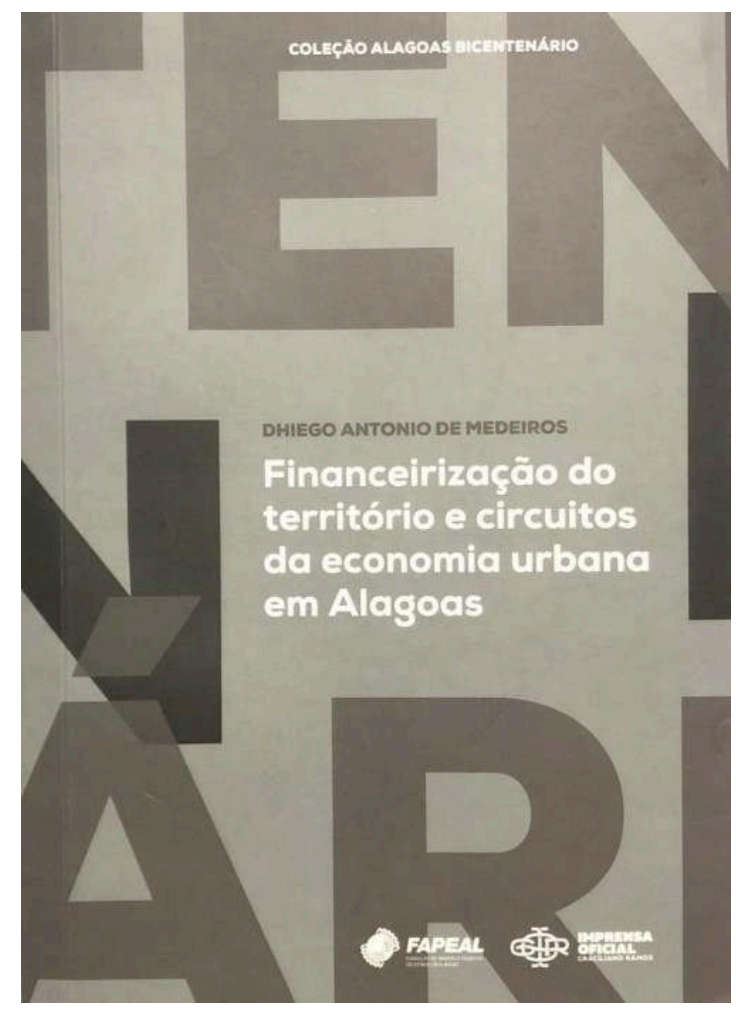

MEDEIROS, Dhiego Antonio de. Financeirização do território e circuitos da economia urbana em Alagoas. Maceió: FAPEAL; Imprensa Oficial Graciliano Ramos, 2018. 318 p.

Financeirização do território e circuitos da economia urbana em Alagoas, obra publicada pela Fundação de Amparo à Pesquisa do Estado de Alagoas/FAPEAL e pela Imprensa Oficial 
Graciliano Ramos, na Coleção Alagoas Bicentenário, é de autoria de Dhiego Antonio de Medeiros, Mestre em Ciências (Geografia Humana) pela Universidade de São Paulo/USP e professor da Universidade Estadual de Alagoas/UNEAL, Campus de União dos Palmares. Fruto de um intenso trabalho de investigação, esta obra é resultado da dissertação de mestrado defendida no Programa de Pós-Graduação em Geografia Humana/PPGH do Departamento de Geografia da Faculdade de Filosofia, Letras e Ciências Humanas/FFLCH, sob a orientação da Professora Dra. Maria Adélia Aparecida de Souza.

2 Medeiros analisa o processo de financeirização do território mediante uma análise da teoria dos circuitos da economia urbana propostos pelo geógrafo Milton Santos, ainda nos idos anos de 1970, trazendo a realidade do sistema financeiro brasileiro e seus reflexos nas regiões, estados e municípios. Com ênfase no estado de Alagoas, permite ao leitor um maior detalhamento e entendimento do que se passa neste território no limiar do presente século. $O$ autor agrega à discussão outros referenciais teóricos que tratam da temática, com uma análise mais atual e tentativa de atualização da teoria dos circuitos da economia urbana, direcionando uma mirada aos novos eventos resultantes das metamorfoses pelas quais o mundo vem passando. Neste viés, e como reflexo da globalização, tem-se possibilitado uma gama de novos usos do território, concomitantemente, a expansão dos novos objetos, que para além de técnicos, apresentam-se com maior carga de ciência e informação, graças ao denominado meio técnico-científico-informacional (SANTOS, [1996] 2008) - conceito importante para o entendimento da variável-chave, finança, e a financeirização do território.

3 Prefaciado por Souza, o livro possui uma estruturação que permite ao leitor ter compreensão da conjuntura econômico-financeira-social do país e, mais empiricamente, de Alagoas. Ao tempo em que gera inquietudes e questionamentos a respeito da realidade de outros estados e regiões, o que, diga-se de passagem, é um caminho de análise que pode ser percorrido por outros pesquisadores. Portanto, não diria que existe um capítulo que seja o ponto culminante do livro, mas cada um apresenta uma discussão ímpar e ao mesmo tempo complementares entre si, o que faz o conjunto da obra ter uma significância aos estudos geográficos que se debruçam acerca da temática. À vista disso, o livro é constituído por seis importantes capítulos, além do prefácio, introdução, conclusões, referências e posfácio, este último escrito pelo Professor Dr. Antonio Alfredo Teles de Carvalho.

$4 \mathrm{Na}$ introdução o autor aponta a importância da Geografia Humana como campo do conhecimento capaz de seguir os caminhos da realidade, analisando-a mediante a variedade de temas a qual já se debruçou e outros que são incorporados conforme as metamorfoses no território e as novas características do mundo presente. É trazida à tona a finança como variável-chave atrelada ao entendimento da categoria geográfica território. Destarte, da atuação do sistema financeiro e bancário, dos circuitos propostos por Santos (superior, marginal e inferior, diferenciados mediante os graus de tecnologia, capital e organização) às desigualdades socioespaciais, são relevantes para o entendimento da financeirização do território como um processo ligado ao modo de produção capitalista, refletido com maior ou menor intensidade nos espaços luminosos e opacos do território brasileiro (SANTOS; SILVEIRA, 2010).

5 Neste percurso, o autor apresenta a obra de Milton Santos - "O espaço dividido: os dois circuitos da economia urbana dos países subdesenvolvido", de 1979 - como contribuição significativa para compreender as economias do Terceiro Mundo. Destaca 
a renda como um indicador empírico na influência maior ou menor do acesso aos bens e serviços. Outro ponto é a desburocratização do crédito como uma forma de aproximar o circuito superior, através dos bancos e financeiras, com o circuito inferior, que historicamente utilizava-se de outras formas de crédito como a agiotagem, aumentando a capilaridade do aparelho bancário pelo país.

6 Os seis capítulos que estruturam essa obra estão sustentados no tripé pesquisa bibliográfica, documental e trabalho de campo, essenciais para compreensão das novas relações entre os circuitos da economia urbana, tendo em vista os novos usos do território, os novos agentes envolvidos, o crescente aumento das técnicas informacionais e as novas relações/acordos/conluios entre as instituições financeiras (públicas e privadas) e o próprio Estado, seja na esfera Federal, estadual ou municipal. Diante das suas diversidades, não é permitido aqui um aprofundamento na análise de cada capítulo, todavia, algumas notas de cada um é relevante para que o leitor se sinta instigado a fazer a leitura da obra como um todo e possa entender o percurso seguido pelo autor na comprovação de sua hipótese: as relações de complementariedade entre os circuitos da economia urbana na realização das atividades do aparelho bancário aumentam sua capilaridade e expressam uma nova forma de financeirização do território brasileiro.

7 O capítulo primeiro, intitulado Formação da rede bancária em Alagoas: das configurações pretéritas à globalização, discute a constituição da rede bancaria em Alagoas, mediante a apreensão da ideia de técnicas e normas, como forma de compreender os novos rearranjos do circuito superior das instituições financeiras no território, com a capital Maceió e o município de Penedo como as duas primeiras zonas de influência da atividade bancária no estado. Para tal, conhecer a dinâmica e diversificação do sistema financeiro, as etapas de formação da rede bancária que o integra e os acontecimentos que marcaram cada período histórico desta formação no território brasileiro e, particularmente, alagoano, é algo imprescindível nessa análise. Assim, Medeiros apresenta alguns marcos importantes: a refundação do Banco do Brasil (BB) no despontar do século XX; surgimento a partir da década de 1920 de cooperativas de créditos e bancos locais; criação da Superintendência da Moeda e do Crédito (SUMOC) em 1945; e o surgimento de bancos de desenvolvimento, como o Banco Nacional do Desenvolvimento (BNDE) e o Banco do Nordeste do Brasil (BNB).

$\mathrm{O}$ autor aborda a interiorização da atividade bancária em Alagoas a partir da expansão da ferrovia e de outros sistemas de circulação para municípios agrestinos, em virtude de determinadas atividades agrícolas e de suas localizações geográficas estratégicas, interligando litoral ao interior, bem como ao Agreste de Pernambuco, o que levou a implantação no município de Palmeira dos Índios da primeira agencia (BB) de todo o Agreste e Sertão alagoano, contando com crescimento das atividades de comércio e serviços, dinamizando os centros urbanos ao seu entorno e criando novas relações econômicas. Medeiros mostra como isto foi essencial para ampliação do número de instituições bancárias no estado, principalmente de redes públicas, consequência da demanda por serviços bancários em zonas econômicas centrais no interior.

Nessa discussão o autor apresenta a Reforma Financeira da década de 1960, marco jurídico-institucional que altera a configuração da atividade bancária e a presença das redes bancárias nos pontos opacos do território brasileiro, com maior ou menor capilaridade de acordo com os interesses dos bancos e dos demais agentes envolvidos; mostra também como o governo brasileiro tentou resolver os problemas da crise econômica das últimas duas décadas do século passado, com a criação do PROER 
(Programa de Estímulo à Reestruturação e ao Fortalecimento do Sistema Financeiro); aponta a crescente desburocratização do acesso ao crédito nos anos 1990 e a consequente presença dos bancos comerciais (BB, Caixa Econômica Federal (CEF) e Bradesco) administrando as folhas de pagamentos municipais em Alagoas, além de outros produtos vendidos aos funcionários destas instituições, atendendo interesses privados em detrimento das necessidades locais.

Em seu segundo capítulo, Atividade bancária e circuitos da economia urbana em Alagoas, Medeiros faz uma discussão da densidade e rarefação (SANTOS; SILVEIRA, 2010) dos fixos geográficos financeiros tradicionais, abrindo espaço para uma discussão sobre o crédito bancário como uma variável dos circuitos da economia urbana no período vigente. Para tanto, as bases técnicas, informacionais e normativas, juntamente com as mais diversas lógicas das grandes corporações, surgem como um caminho pelo qual os bancos passaram a atuar também nas áreas opacas do território, porém mantendo concentração de certas atividades nas cidades mais dinâmicas, possuindo, consequentemente, maior densidade de fixos geográficos bancários. No caso de Alagoas, o autor aponta a presença das Agências Bancárias, Postos de Atendimento Avançado (PAA's) e Postos de Atendimento Bancário (PAB's) pelos quais as instituições financeiras atuam, com destaque para Maceió, que concentra a maior quantidade de bancos. Sobressaem os bancos privados, muito relacionados com o circuito superior, principalmente os estrangeiros, Medeiros mostra como buscam as áreas mais luminosas objetivando a drenagem de capital, a exemplo do HSBC Bank Brasil, Banco Santander, Itaú Unibanco e outros com menos capilaridade como o Banco Industrial e Comercial (BICBANCO), Daycoval e o PSA Finance Brasil.

11 Outro ponto apresentado é o papel dos bancos federais na efetivação de políticas públicas do Governo Federal e, consequentemente, o fomento de atividades do circuito inferior, com uma política de bancarização das populações que vivem em lugares de difícil acesso. Ao tempo em que proporciona aumento das contas bancárias abertas, indução a sociedade a utilizar diversos serviços financeiros, bem como tendo nos convênios com as prefeituras, para a administração da folha de pagamento, um dos novos serviços financeiros que tem proporcionando maior capilaridade para o interior e redução da concentração bancária na Capital. É destacado também a oferta de produtos, como o cartão de credito e empréstimos consignados, assim como o papel desempenhado pelo BNB, com grande capilaridade no Nordeste, de atuação exclusiva com Carteira de Desenvolvimento em Alagoas, permitindo o incentivo à atividades agroindustriais e linhas de financiamento a pequenos produtores.

Com a nova racionalidade que se instala no território, o crédito bancário institucional tem assumido posição central nas atividades econômicas, extrapolando os limites do circuito superior e capilarizando-se pelo circuito inferior, onde certa parcela da população, antes desprovida deste serviço, passa a contar com este crédito bancário. Assim, Medeiros evidencia que os bancos se ajustam as demandas sociais do período e que o circuito superior vai se remodelando frente a criação de novas estratégias do comércio moderno. São os novos arranjos organizacionais, agregando às instituições financeiras bancárias aquelas não-bancárias, com empréstimos à pessoa física, aumentando o poder de capilarização com crédito rápido, sem muita burocracia e sem necessidade de estrutura física complexa. Tem-se portanto, a creditização do circuito inferior. Nos anos 2000 a abertura do mercado de crédito consignado para aposentados e pensionistas do INSS foi outra forma de impulsionar o crédito institucional, com 
alguns bancos à frente da intermediação da concessão de crédito para este circuito: BB, Itaú, Unibanco, Bradesco, CEF e Santander.

No capítulo terceiro, Uso corporativo do território alagoano e a hipercapilaridade das finanças vemos uma discussão em torno das novas topologias e do uso corporativo do território, mediante apoio das novas bases técnicas e da informação, que dão suporte aos novos fixos geográficos e possibilita maior fluidez dos sistemas de ações e a chegada de topologias bancarias em espaços nunca antes pensado. Com a capilaridade das finanças pelo território, com interferência do circuito superior sobre o inferior, o autor busca mostrar como ela se dá de forma desigual e o desnivelamento econômico existente a partir da realidade de Alagoas, que tem-se tornado mais visível diante da incorporação da variedade de serviços bancários e não bancários às agências e postos de atendimento já instalados. Tem-se uma crescente creditização do território e a instalação de novos canais eletrônicos em espaços ausentes da rede bancária tradicional,

O ATM (Automatic Teller Machine), como técnica bancária informacional e com baixo custo, surge como tentativa de aumentar a lucratividade dos bancos e dar maior fluidez aos serviços financeiros, incorporando diversas funções e contribuíram para desafogar os serviços financeiros das agências, fazendo parte dos dois circuitos e da dinâmica financeira do território. Em Alagoas a predominância é para os Caixas Eletrônicos restritos, aqueles que estão juntos as Agências e Postos de Atendimento da instituição que detém o controle do equipamento. Nas cidades de maior centralidade tem-se maior concentração de ATM (restrito, compartilhado ou aberto) e que estão juntos às lojas, supermercados, universidades etc. Outros três canais apresentados e que ganharam espaços em virtude da desburocratização do crédito e do crescente uso da internet foram: o Banco por internet, meio pelo qual o sistema bancário vem conseguindo atingir grande parcela de excluídos de serviços financeiros; os serviços de Call Centers, que surgem como forma de solucionar o problema da distância dos centros em relação as áreas opacas do território; e o mobile banking, criado pelas instituições financeiras para que o cliente tivesse o banco em suas mãos.

Finalizando o capítulo discute-se a capilaridade das finanças através do "dinheiro de plástico", os cartões de crédito, que possibilitou à camada mais pobre ingressar no circuito superior, facilitando a venda de bens e acelerando a circulação da moeda informacional no território. Assim, grandes redes varejistas introduziram no mercado os Cartões de Loja: cartões Private Label (Renner e C\&A - bandeira da loja), Co-branded (Magazine Luiza e Pão de Açúcar - bandeira da loja e da administradora do cartão: Mastercard, Visa etc.) e Open Private Label, resultante da disputa pelo domínio entre o grupo Walmart e Pão de Açúcar. Com isto, as lojas e grupos estão cada vez mais adentrando o circuito inferior e as cidades de menor dinamismo.

16 No capítulo quatro, Correspondentes no país: uma forma-conteúdo do sistema financeiro nacional, o autor apresenta uma periodização para compreender a atuação dos correspondentes no Brasil, com três grandes períodos, para em seguida apontar a proeminência dos mesmos em zonas opacas do território de Alagoas. Para tanto, tem-se como ponto de partida o início do século XX até o ano de 2013, trazendo à tona os principais eventos que marcaram a dinâmica do sistema bancário brasileiro em cada período histórico. Em sua proposta de periodização e respectiva analise, Medeiros se apodera de variáveis importantes para entender a atuação de um evento no espaçotempo: processo, forma, estrutura e função (SANTOS, [1985] 2008). 
17 O autor mostra como os correspondentes foram ganhando novos contornos e funcionalidades, com boas margens de lucros que as instituições financeiras iam conseguindo através deles. Dentre as atividades mais executadas pelos correspondentes estão pagamentos e recebimentos de títulos, empréstimos e financiamentos, movimentações de contas e cartão de crédito. É também visto nesta análise que os correspondentes, por um lado, aumentam as possibilidades de penetração das atividades bancárias no território, por outro, instala nova organização na divisão do trabalho bancário, o que poderia ser considerado como uma forma de terceirização do trabalho. Este tipo de trabalho tem levado a alguns órgãos de defesa a mostrar o quanto esse fixo e a mão de obra ligada a ele (especialmente os "pastinhas", apresentados no capítulo 5) são canais propícios para diversas irregularidades e crimes no mundo financeiro, proporcionando ilegalmente maior lucro. Processo caracterizado como "lavagem de dinheiro".

18 Na sequência, Medeiros mostra como se dá a atuação dos correspondentes em zonas opacas do território, trazendo como exemplo o caso alagoano, onde passou de 197 correspondentes em 2002 para 3.700 no dia 02 de setembro de 2013. Isto evidencia o papel deste fixo geográfico em lugares distantes em substituição aos fixos bancários tradicionais, sendo visível a geografização das finanças no território e o fortalecimento da relação dos bancos com as atividades do circuito superior.

19 O quinto capítulo, Agentes de crédito: um nexo entre os circuitos da economia urbana nas cidades brasileiras, apresenta os agentes de crédito a partir da realidade de três cidades localizadas no Agreste alagoano. Com a criação em 2003 do credito consignado surge o agente de crédito - os pastinhas -, profissional autônomo que atua em nome do correspondente, com a função de "buscar" clientes para oferecer empréstimo consignado, principalmente para funcionários públicos, aposentados e pensionistas do INSS, com debito em "folha" ou consignado, sem risco de inadimplência. Eles passam a exercer papel de intensa capilarização dos serviços financeiros mediante o acesso aos serviços bancários básicos por parte da população.

20 O autor assim apresenta três cidades do interior alagoano para mostrar como se dá essa relação dos pastinhas: Girau do Ponciano, Traipu e Campo Grande. Cidades com papel de centros locais e sem influência sobre outros centros, com economia dominada praticamente pelo circuito inferior, tendo no setor bancário um dos poucos elementos do circuito superior da economia urbana. Outro destaque é o papel da Promotora de Crédito, empresa terceirizada que firma convenio com um ou mais bancos e fica responsável por uma quantidade de empréstimos por mês, localizada nas principais cidades de cada estado, com tarefa principal de oferecer material de publicidade e treinamento para o Correspondente.

21 O capítulo seis, Divisão do trabalho e ação do capital em tempos de globalização, encerra o conjunto da obra discutindo o acirramento da divisão do trabalho e regulações flexíveis no mundo dos bancos, bem como a relação do sistema financeiro nacional com a população de baixa renda. É uma discussão que Medeiros já veio fazendo durante todo o livro, mostrando que dentro do circuito superior os principais mecanismos reguladores da dinâmica financeira é, em especial, a norma e a técnica, que atuam no reordenamento do trabalho bancário, diferentemente do circuito inferior onde o trabalho intensivo se sobressaí em substituição as carências de técnica e capital. Assim, com o reordenamento da oferta e demanda de serviços, a partir dos aspectos técnicos, normativos e mercadológicos, o sistema bancário passa a dar preferência por canais 
eletrônicos, com crescente uso de tecnologias da informação e, consequentemente, redução do quadro de funcionários e reordenando as funções executadas pelos bancários. Ao tempo em que regulamenta a prestação de serviços por organizações não bancarias e aumenta o quantitativo de intermediários, criando novas relações entre o banco e os espaços opacos do território.

É apontado que a atividade do correspondente é importante por sua capacidade de adaptação e de aproximação com as camadas mais populares. Muitas vezes o correspondente só atinge este circuito mediante agentes do próprio circuito, tendo em vista as características de solidariedade orgânica e não institucional, onde se valem do conhecimento do território para a realização da atividade. Os agentes de crédito do inferior acabam por criar vínculos com o superior mediante o trabalho exercido para um determinado correspondente, proliferando-se e aumentando as possibilidades de oferta de serviços financeiros aos mais pobres, com o banco canalizando o faturamento do trabalho de todos os demais atores, e o cliente, o responsável por arcar com os custos de todos os demais envolvidos na operação.

São as finanças, portanto, a mola dinâmica da vida econômica e social, onde as instituições financeiras passaram a comandar os fatores que norteiam o cotidiano da própria sociedade, determinando a expansão das formas de consumo às classes mais populares, bem como a execução de atividades a partir dos novos fixos ligados ao inferior. Nesta relação tem-se um nexo-chave, o crédito, que com a sua desburocratização abriu espaço para uma atuação maior das instituições financeiras. Assim, a banalização do credito e seu adiantamento em diversas parcelas é uma das formas encontradas pelo superior para alcançar as camadas mais baixas da sociedade, com lucros exorbitantes para os atores do superior e endividamento crescente das classes do inferior, mediante as altas taxas de juros cobradas. Destaca-se como via de expansão das modalidades financeiras no território o próprio Estado, que tem possibilitado a aproximação das classes mais populares ao sistema financeiro, a exemplo de programas de distribuição de renda como o Programa Bolsa Família (PBF), onde milhões de pessoas recebem recursos públicos via contas bancárias.

Diante do exposto pelo autor, podemos concluir que em sua análise a finança se constitui numa variável-chave, caracterizada pelo papel exercido pelo dinheiro em suas várias formas nos diversos lugares, a exemplo do que é apresentado para o estado de Alagoas, mostrando o sistema bancário como a maior expressão do sistema financeiro, com as categorias normas e técnicas sendo essenciais para uma leitura do processo de constituição da rede bancária. Neste sentido, o entendimento dos novos nexos entre o circuito superior (o banco), o superior marginal (promotoras de créditos e correspondentes) e o inferior (agente de crédito) apontados no decorrer do livro por Medeiros, tornam-se indispensáveis na análise da financeirização do território alagoano. Portanto, a obra é uma excelente contribuição aos estudos geográficos e outras áreas do conhecimento, sendo recomendável sua leitura à pesquisadores que trabalham, direta ou indiretamente, com esta discussão. 


\section{BIBLIOGRAFIA}

SANTOS, M. O Espaço Dividido: os dois circuitos da economia urbana dos países subdesenvolvidos. São Paulo: Editora da Universidade de São Paulo/EDUSP, [1979] 2008. 440p. $120 \mathrm{p}$. . Espaço e Método. São Paulo: Editora da Universidade de São Paulo/EDUSP, [1985] 2008.

. A natureza do espaço: técnica e tempo, razão e emoção. São Paulo: Editora da Universidade de São Paulo/EDUSP, [1996] 2008. 384p.

SANTOS, M.; SILVEIRA, M. L. O Brasil: território e sociedade no início do século XXI. 13ª ed. Rio de Janeiro: Record, 2010. 475p.

\section{AUTOR}

\section{PAUL CLÍVILAN SANTOS FIRMINO}

Doutorando do Programa de Pós-Graduação em Geografia Humana/PPGH do Departamento de Geografia da Faculdade de Filosofia, Letras e Ciências Humanas/FFLCH da Universidade de São Paulo/USP, Brasil.

Bolsista da Fundação de Amparo à Pesquisa do Estado de São Paulo/FAPESP (processo 2017/22120-9), com orientação da Profa. Dra. Rosa Ester Rossini. 